\title{
Ultra high performance concrete shear walls
}

\author{
YiChen Fang* \\ Shandong University of Construction \\ 86-15668360750
}

\begin{abstract}
The history of the development of Ultra-High Performance Concrete (UHPC) shear walls and the current status of today's research as well as the future development prospects are comprehensively collated. The analysis process and conclusive results of the present-day domestic and international research on UHPC shear walls are highlighted. The load displacement curves, hysteresis curves and skeleton lines of ultra-high performance concrete shear walls under different experimental loads are collated and compared. Integrate the corresponding equations for shear bearing capacity and equations for the overall specimen load displacement curves. A finite element model of the ultra-high performance concrete shear wall is established to simulate and perform non-linear finite element analysis of its force process under unidirectional horizontal loading.
\end{abstract}

\section{Background section}

\subsection{Introduction to UHPC shear walls}

In modern civil engineering, new materials and their material properties are being investigated in various countries. Ultra-High Performance Concrete (UHPC) is one of them. Ultra-High Performance Concrete (UHPC) is considered to be the most innovative cement-based engineering material of the last 30 years. It is widely used in large span or storm resistant structures due to its high durability and abrasion and storm resistance properties. It has unlocked a new horizon for the civil engineering industry. The dimensions of UHPC structures are between those of ordinary concrete structures and steel structures for the same load-bearing capacity, and the mechanical properties of properly reinforced UHPC structures are close to those of steel structures. UHPC utilises fine aggregates and achieves the tensile and strain-reinforcing behaviour of the material through the close adhesion of strong steel fibres and their gel. The ultimate pressure strain varies between $0.004-00.0052$, depending on the number of steel fibres. Creep is very small under longterm loading (only about one tenth of that of normal concrete). Shrinkage occurs very little under the heat curing conditions of [1]. Over the last two decades, UHPC has gained increasing interest in many countries and regions, with applications ranging from building components, bridges, architectural features, repair and restoration, windmill and utility towers, to oil and gas industry applications, offshore structures, hydraulic structures and cover materials. Many academics have also tested the benefits and current status of UHPC in terms of its own performance and the buildings constructed from it. Wang and Gao [2] et al. used UHPC material cast axial tensile specimens with different strain forms to measure the axial tensile mechanical properties of the material, as well as experimental monotonic and cyclic loading to observe the tensile properties of the material to establish stress-strain curves, followed by the establishment of an intrinsic structure model and the inference of the axial tensile damage equation of the specimen, and finally the use of finite element simulation to verify the rationality and accuracy of both.

Zeng and Luo [3] et al. collated and introduced the permeable ultra-high performance concrete UHPC material to establish an assembled traveling steel frame bridge, which is a novel structural form of arch bridge utilizing the advantageous performance of UHPC material, solving the problems of traditional arch bridge such as easy cracking, low bearing capacity, long construction time of cast-in-place, and beautiful shape, this construction method is less in China and less construction experience, which introduced the design points of the bridge, construction method and construction monitoring, providing the construction experience of this type of bridge, in providing help for the subsequent promotion of this type of bridge.

Wang [4] summarised the prospects for the use of UHPC by analysing and summarising the application of UHPC materials in bridges in various countries and the current construction methods and progress.

So far, many studies have been carried out on UHPC beams, columns, beam-column nodes and piers, but relatively it has been less studied in shear wall structural members, mainly due to the relative lag of relevant basic research. This article is to use UHPC as shear wall material using ABAQUS simulation to establish its intrinsic structure model and fatigue capacity test. The corresponding research on UHPC as a structural material for shear walls is relatively scarce but there are some predecessors who have conducted some tests on it.

$\mathrm{Li}$ and Wei et al [5] designed seven high-strength concrete shear wall specimens with different forms of edge-constrained members and one high-strength concrete shear wall specimen with normal reinforcement, which were subjected to low perimeter repeated horizontal loads. It was obtained from the experiments that for shear walls with shear-to-span ratio $\lambda \geqslant 2$, the seismic performance of high-strength concrete shear walls could

\footnotetext{
* Corresponding author: 2506281851@qq.com
} 
be significantly improved by setting high reinforcement rate concealed columns or end columns in the highstrength concrete shear walls and appropriately increasing the reinforcement rate of horizontal and vertical distributed reinforcement.

One of them, Zhong and Tong [6], used finite element simulation to establish a UHPC shear wall model to simulate the applied horizontal loads. The stress-strain equations and corresponding relationship curves were derived from the UHPC principal structure model, and the load-displacement curves of real specimens were derived by building solid specimen models from other literature and then compared with their own simulated experimental models to verify the accuracy of their own experiments and to summarise the differences between the two and to analyse the reasons. The effects of the axial compression ratio, shear-to-span ratio, reinforcement rate of concealed column longitudinal bars, reinforcement rate of concealed column hoop bars and reinforcement rate of distributed reinforcement on the shear bearing capacity of UHPC shear walls were analysed. Corresponding control curves were established to highlight the magnitude and magnitude of the effects of the respective variables on the materials.

Subsequently, Zhang, Liu, Li and Chen et al [7] analysed the research status of UHPC at home and abroad in terms of UHPC matching ratio, doped fibres and nano-materials, summarised the research status of ultra-high performance concrete UHPC at that time construction process as well as outlook, and also analysed and summarised the internal and external research on UHPC in structural applications. It provides an effective reference for the next UHPC research development.

Tong and Xiao et al [8] cast an ultra-high performance concrete (UHPC) shear wall to which vertical and horizontal biaxial stresses were applied. To verify its resistance to shear bearing capacity low circumferential repeated loading was applied to study its shear bearing capacity and fatigue strength, and it was concluded that UHPC has high cracking resistance and ultimate bearing capacity. The type and extent of cracking in the specimens were analysed: the number of cracks in the specimens was large and the specimens did not exhibit the typical $\mathrm{x}$ shaped cracks. The cracking load was $65 \%$ of the peak load and the UHPC shear wall showed high cracking resistance and ultimate load carrying capacity. The deformation performance of the specimens met the requirements of the current code. A formula for calculating the cracking load of UHPC shear walls with inclined sections was also derived and the cracking load of the specimens was calculated. Compared with the measured results, the formula is highly accurate and can be used to calculate the cracking load of inclined sections of UHPC shear walls. A formula for calculating the load carrying capacity of the diagonal section of UHPC shear walls is presented and the load carrying capacity of the specimens is calculated. Compared with the measured results, the formula has a high accuracy and can be used to calculate the shear bearing capacity of UHPC shear walls.

Nong and Zheng etc. [9] used UHPC material bonded to each shear wall structure to study the application of ultra-high performance concrete in assembled building shear walls, verifying that UHPC material can carry out effective force transfer and can make the assembled specimen capacity equivalent to that of cast-in-place specimens its crack resistance, strength and stiffness or even better than fully cast-in-place.

$\mathrm{Xu}$ [10] constructed a coarse aggregate UHPC material and a short coarse aggregate UHPC column with hoop restraint, experimented and tested the material ratio of the specimen as well as various mechanical properties, established the axial compression stress-strain relationship curve of the short UHPC column with hoop restraint, and obtained the optimal water-cement ratio control value and the conclusion that the amount of steel fibre dosing affects the strength of the material itself. The experimental results are compared and the restraint mechanism of hoop-constrained UHPC short columns is discussed as the combined effect of internal and external restraint respectively. The calculation method of the hoop restraint stress is derived and the corresponding peak stress and peak strain equations are given to verify the agreement with the experimental results. The restraint mechanism is also derived and a uniaxial restraint intrinsic structure model is established. A large span bridge built with UHPC material is also simulated to analyse its reasonableness and suitability.

Xue [11] studied RUHPC combined precast shear walls to analyse their force performance. Firstly, he proposed a numerical model for the tensile strengthening effect of RUHPC based on which the average stresses in steel reinforcement and UHPC during tensile strengthening were calculated and the tensile principal structure of steel reinforcement and UHPC considering the tensile strengthening effect was proposed. The uniaxial tensile tests on the specimens were carried out by varying the steel fibre admixture and reinforcement rate, and the validity of the tensile strengthening instantiation was demonstrated. Secondly, the proposed tensile instantiation of RUHPC considering the tensile strengthening effect is applied to the softened truss model. The softening coefficient of UHPC is fitted based on the experimental literature and the compressive instantiation of UHPC considering softening is proposed in combination with the present compressive instantiation of UHPC. The corresponding material ontology model was developed for finite element simulation and compared with the experimental results to demonstrate the validity of the softened truss model for RUHPC material to simulate RUHPC shear specimens. Finally, the second developed material ontology was subjected to finite element simulations of concrete and RUHPC shear walls and compared with literature tests to demonstrate that the finite element model can accurately describe the shear mechanical response of shear walls. Based on this finite element model, a simulation of the RUHPC combined precast shear wall was carried out. Parametric analyses based on the simulation results were also carried out. The results show that the RUHPC combined nodal slab can improve the bending and shear load capacity of the structure and increase the deformation capacity of the structure. Based on the lower limit method of plastic limit analysis, the bending load capacity equation of RUHPC 
precast shear wall is proposed, and the shear load capacity calculation method of RUHPC precast shear wall is proposed based on the softened tension-compression bar model. The finite element simulations based on the secondary developed structure are also used to verify the bending capacity equation and shear capacity calculation method. This paper is a simulation and data analysis of the modelling of UHPC material acting as a shear wall as the centre of the study. Comparisons with previous experiments are made to verify the validity of the modelling. Simulated unidirectional horizontal load simulation experiments are also carried out on the specimens. To study their shear bearing capacity.

\subsection{Introduction of corresponding experimental curves}

The stress-strain relationship curve for UHPC shear wall reinforcement and the load displacement curve established by Zhong and Tong et al. It was modelled using ABAQUS for the length*width*height $(700 \mathrm{~mm} * 100 \mathrm{~mm} * 1400 \mathrm{~mm})$ model using HPB300 reinforcement as the wall

UHPC material shear walls are modelled using vertical and horizontal distribution reinforcement, concealed column hoops and HRB400 as concealed column longitudinal reinforcement. The overall load displacement curve is studied. One of these curves is that of the specimen in [4] and the curve obtained in the simulation modelling experiments.

The corresponding derived equation:

$$
y=147.6 \ln (x)+145.94
$$

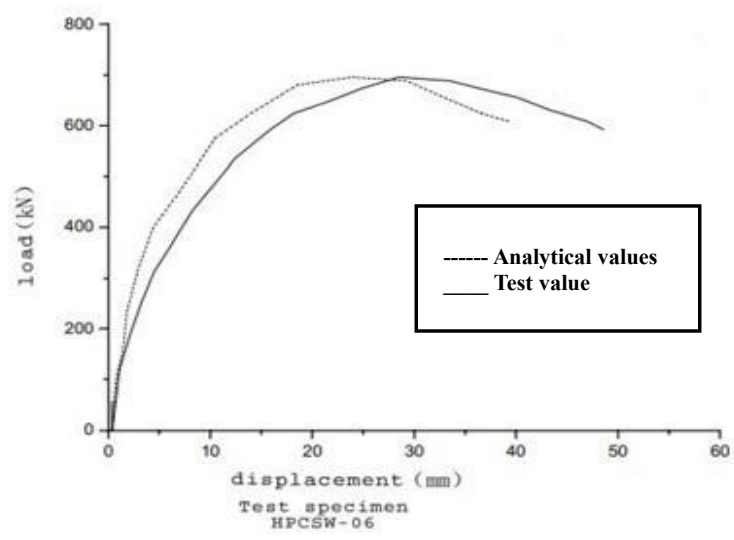

Fig. 1. The conclusion drawn from the curves is that the shear capacities of the two are relatively similar, but the shape of the load-displacement curves deviates, mainly because the initial stiffnesses of the analysed curves are both slightly higher due to the lack of consideration of the adhesive slip between the reinforcement and the concrete.

The corresponding influence curves were also established separately for different influence factors. As shown in Figures 2, 3 and 4

Axial pressure ratio:

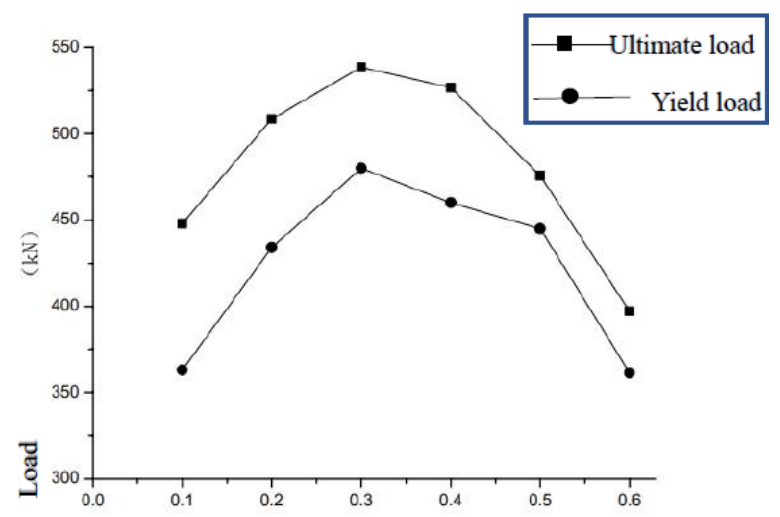

Fig. 2. Axial pressure ratio and ultimate and yield loads.

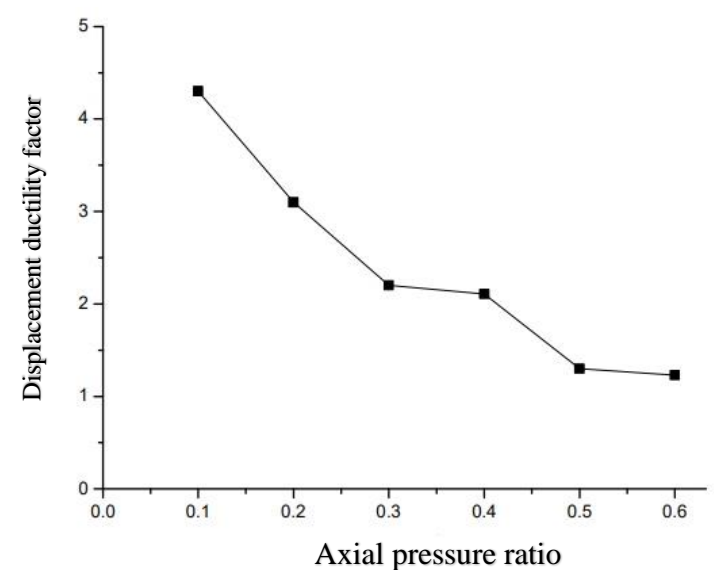

Fig. 3. Axial pressure ratio and displacement ductility factor.

Shear-to-span ratio:

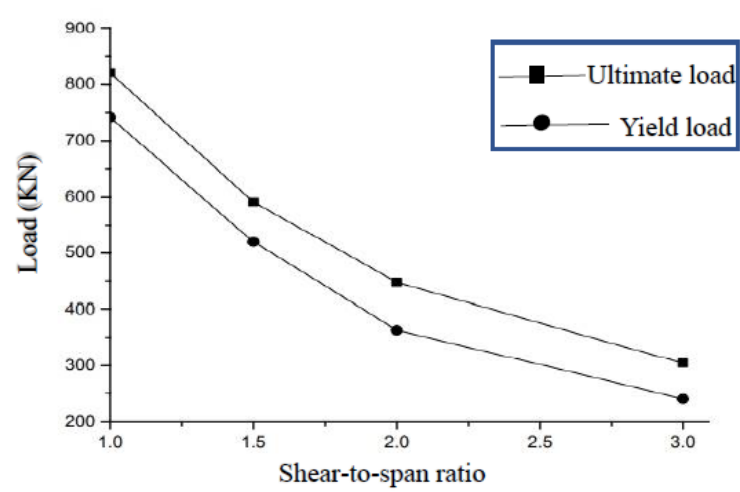

Fig. 4. Shear to span ratio and ultimate and yield loads.

A corresponding study of the role of UHPC as a connection for assembled shear walls was investigated by Nong and Zheng et al. A low circumferential repeated load test using constant axial pressure was established for length*width*height $\left(1300 \mathrm{~mm}^{*} 160 \mathrm{~mm}^{*} 2800 \mathrm{~mm}\right)$ and the crack form of the specimens was studied.

The hysteresis curves of the corresponding specimens were obtained. The shape of the hysteresis curves was bowed, and the curves were all full, with good energy dissipation capacity. Before cracking, the specimens were in an elastic state and the hysteresis curves were basically straight, with no residual deformation in the specimens. After yielding, the hysteresis loops are fuller and each peak point of the hysteresis loops is basically kept in a 
horizontal line, the specimen has good ductility and energy dissipation capacity. As shown in Figure 5 and 6.

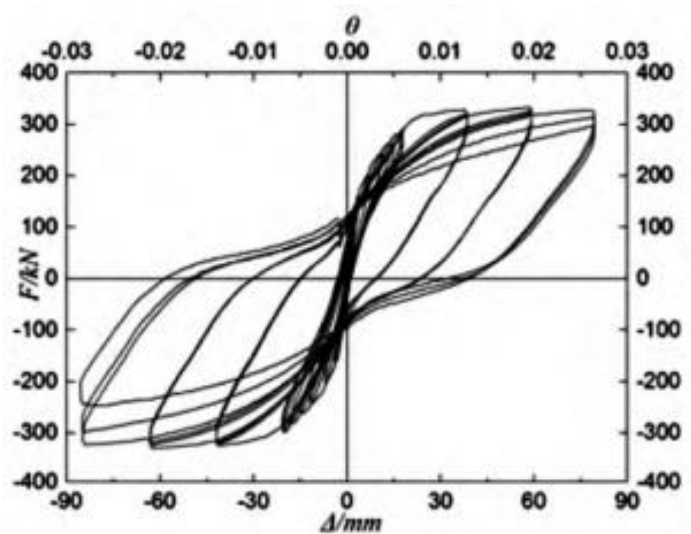

Fig, 5. SW1 hysteresis curve

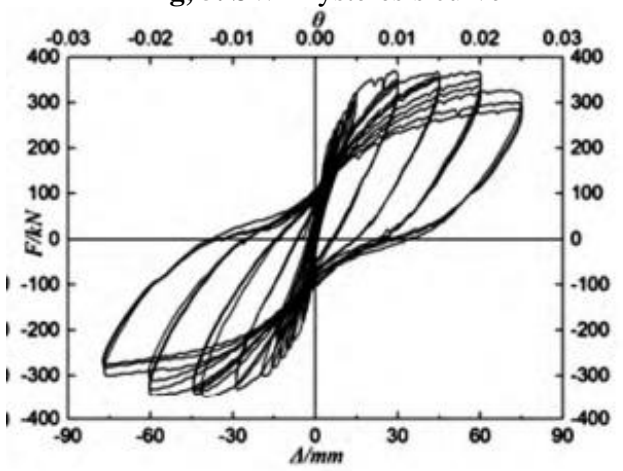

Fig. 6. PW1 hysteresis curve.

As well as deriving the specimen skeleton line. As shown in Figure 7.

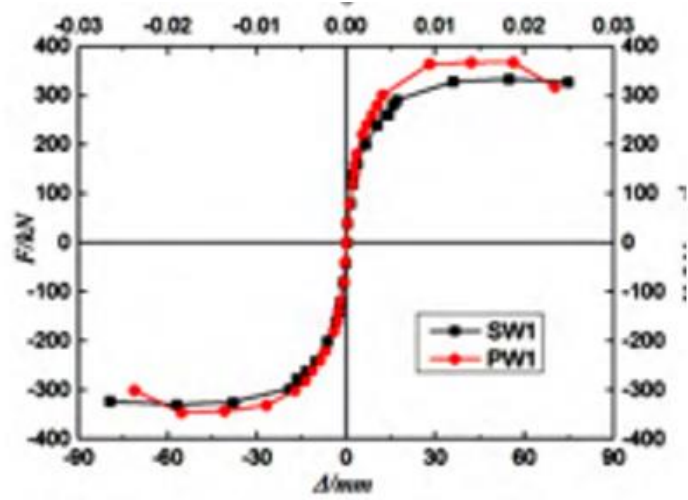

Fig. 7. specimen skeleton line skeleton curves for different specimens.

The number of values corresponding to each of its characteristic points is obtained. As in Form 1.

\section{Form 1}

\begin{tabular}{|cccccccc|}
\hline \multirow{2}{*}{$\begin{array}{c}\text { Specimen } \\
\text { number }\end{array}$} & $\begin{array}{c}\text { Cracking } \\
\text { load } \\
\text { Fcr/kN }\end{array}$ & $\begin{array}{c}\text { Cracking } \\
\text { displacement } \\
\Delta \mathrm{cr} / \mathrm{mm}\end{array}$ & $\begin{array}{c}\text { Cracking } \\
\text { displacement } \\
\text { Corner } \theta \mathrm{cr}\end{array}$ & $\begin{array}{c}\text { Yield } \\
\text { Load } \\
\text { Fy/kN }\end{array}$ & $\begin{array}{c}\text { Yield } \\
\text { displacement } \\
\Delta \mathrm{y} / \mathrm{mm}\end{array}$ & $\begin{array}{c}\text { Yield } \\
\text { displacement } \\
\text { Corner }{ }^{\mathrm{y}}\end{array}$ \\
\hline SW1 & Positive & 160.59 & 3.38 & $1 / 870$ & 258.24 & 12.69 & $1 / 232$ \\
\cline { 2 - 8 } & Negative & 160.49 & 3.39 & $1 / 870$ & 250.42 & 12.46 & $1 / 237$ \\
\cline { 2 - 8 } & Average & 160.54 & 3.39 & $1 / 870$ & 254.33 & 12.58 & $1 / 234$ \\
\hline PW1 & Positive & 180.48 & 3.72 & $1 / 793$ & 271.27 & 10.16 & $1 / 290$ \\
\cline { 2 - 8 } & Negative & 180.29 & 4.32 & $1 / 683$ & 259.48 & 12.12 & $1 / 242$ \\
\cline { 2 - 8 } & Average & 180.39 & 4.02 & $1 / 734$ & 265.38 & 11.16 & $1 / 264$ \\
\hline
\end{tabular}

\begin{tabular}{|c|c|c|c|c|c|c|c|c|}
\hline \multicolumn{2}{|c|}{ Specimen } & $\begin{array}{l}\text { Peak } \\
\text { Load }\end{array}$ & $\begin{array}{c}\text { Peak } \\
\text { Displacement }\end{array}$ & $\begin{array}{c}\text { Peak } \\
\text { Displacement }\end{array}$ & $\begin{array}{l}\text { Limit } \\
\text { Load }\end{array}$ & $\begin{array}{c}\text { Limits } \\
\text { Displacement }\end{array}$ & $\begin{array}{c}\text { Limits } \\
\text { Displacement }\end{array}$ & $\begin{array}{c}\text { Ductility } \\
\text { Coefficient }\end{array}$ \\
\hline \multicolumn{2}{|c|}{ number } & $\mathrm{Fp} / \mathrm{kN}$ & $\Delta \mathrm{p} / \mathrm{mm}$ & Corner ${ }^{\theta} \mathrm{p}$ & $\mathrm{Fu} / \mathrm{kN}$ & $\Delta \mathrm{u} / \mathrm{mm}$ & Corner $\theta \mathrm{u}$ & $\mu \Delta$ \\
\hline \multirow[t]{3}{*}{ SW1 } & Positive & 333.16 & 57.89 & $1 / 51$ & 327.91 & 78.86 & $1 / 37$ & 6.21 \\
\hline & Negative & 330.01 & 61.71 & $1 / 48$ & 322.67 & 84.30 & $1 / 35$ & 6.77 \\
\hline & Average & 331.59 & 59.80 & $1 / 49$ & 325.29 & 81.58 & $1 / 36$ & 6.48 \\
\hline \multirow[t]{3}{*}{ PW1 } & Positive & 367.58 & 59.8 & $1 / 49$ & 327.12 & 67.76 & $1 / 44$ & 6.67 \\
\hline & Negative & 345.75 & 58.95 & $1 / 50$ & 300.65 & 75.86 & $1 / 39$ & 6.24 \\
\hline & Average & 356.67 & 59.38 & $1 / 50$ & 313.89 & 71.81 & $1 / 41$ & 6.43 \\
\hline
\end{tabular}

Degradation curves: As shown in Figure 8.

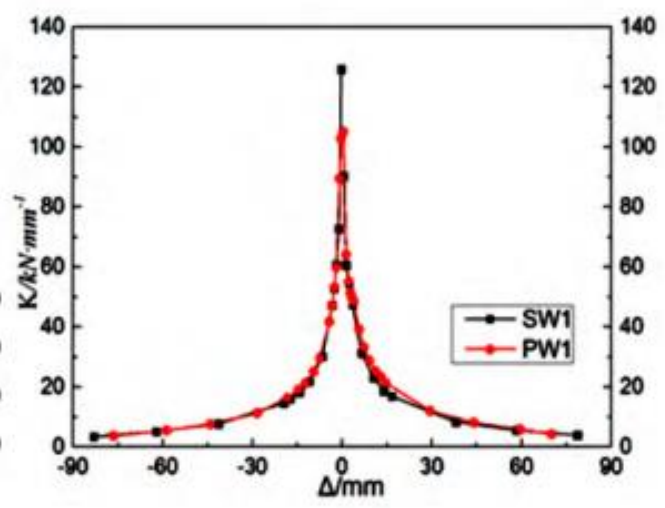

Fig. 8. Degradation curves.

Tong and Feng et al. established UHPC ultra-high strength concrete shear wall specimens with a length*width*height $\quad(1000 \mathrm{~mm} * 80 \mathrm{~mm} * 1000 \mathrm{~mm})$ reinforcement distribution as shown in Figure 9 below; the loading schematic is shown in Figure 10. 


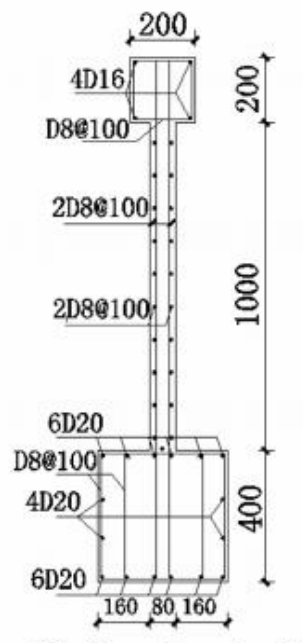

(b). Elevation view 2-2

Fig. 9. Specimen size and reinforcement

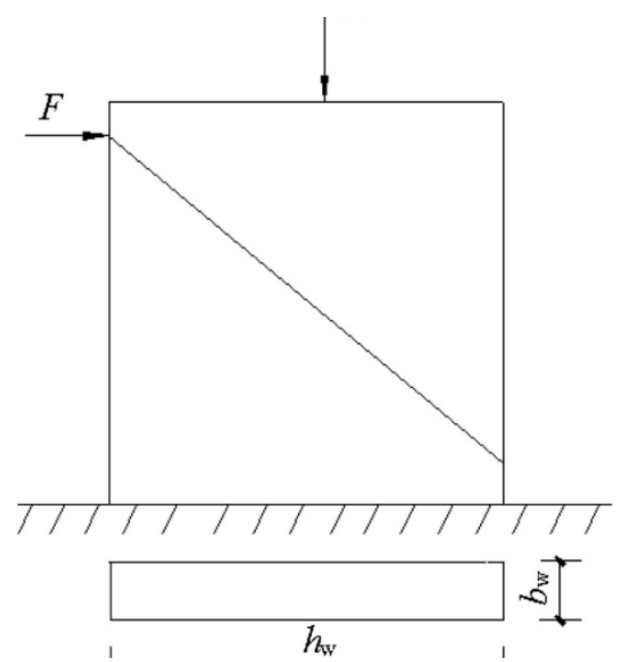

Fig. 10. Loading diagram.

Repeated loading of the biaxial longitudinal and transverse low circumference: see Fig. 11 for cycles.

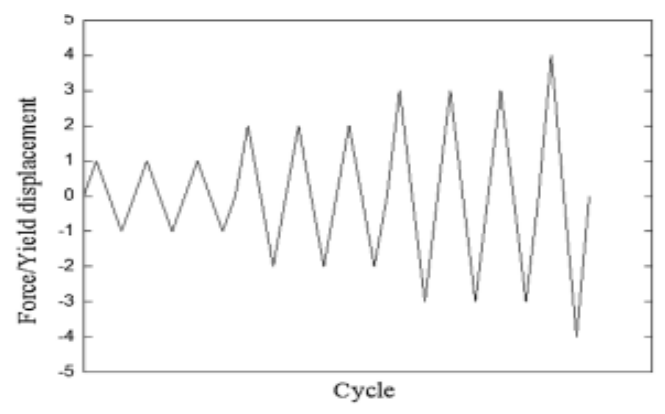

Fig. 11. Longitudinal and transverse low circumferential repetitive loading curves.

Its hysteresis curve is obtained: see Figure 12.

As well as analysing the form, size and width of their crack distribution.

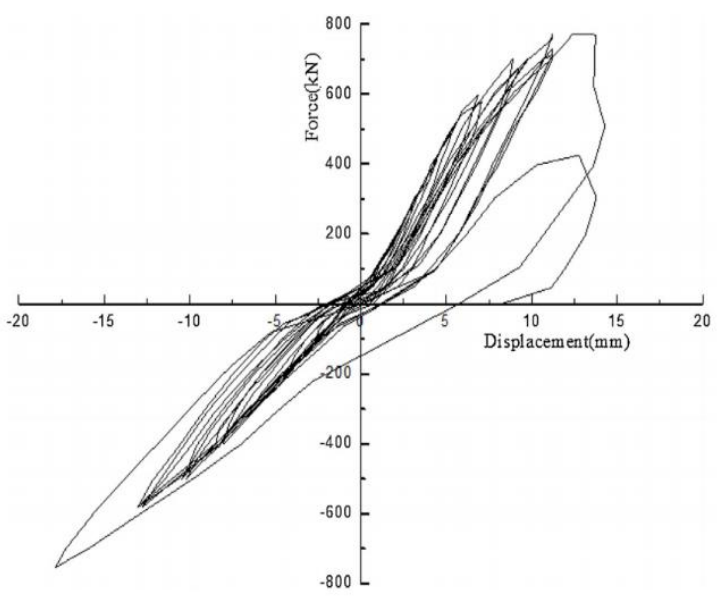

Fig. 12. Specimen hysteresis curves.

The shear displacement component at the top of the specimen is shown in the figure: see Figure 13.

The curve does not change much in the early part of the curve, the overall trend is slowly increasing until 6 , almost flat between 6 and 7, and the displacement starts to change significantly around 7 ; the most dramatic increase is seen in the period 10-12, growing twice as much as before, from 12 onwards the change in magnitude decreases and there is a slight tendency to level off.

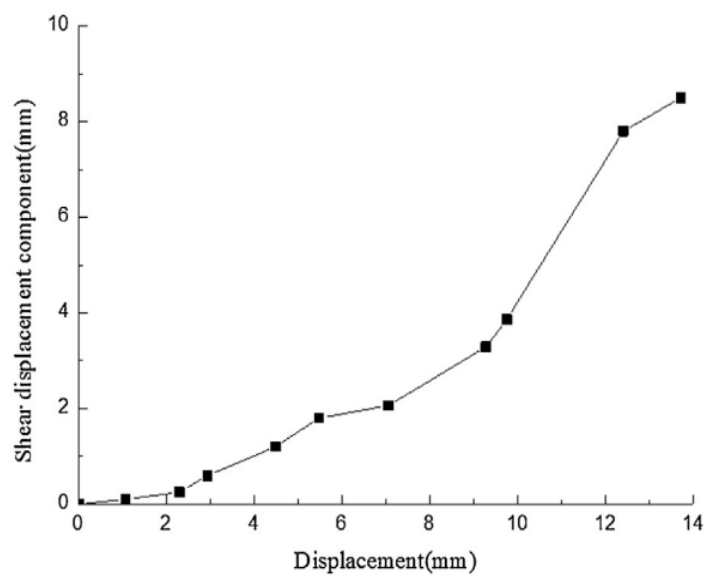

Fig. 13. Derive the corresponding formula.

Under the action of axial force, N, horizontal force, F, the shear wall produces a shear wall with the main tensile stress reaching the initial crack strength of the UHPC. The maximum shear stress tmax is obtained and can be expressed as follows:

$$
\tau_{\max =1.5 \frac{F_{c r}}{h_{w 0} b_{w}}}
$$

The main tensile stresses in UHPC for the calculation of shear wall cracks are the initial crack strengths:

$f_{\text {to }}$ :

$$
f_{t 0}=-\frac{\sigma_{n}}{2}+\sqrt{\frac{\sigma_{n}^{2}}{4}+\tau_{\max }^{2}}
$$


where $\sigma_{\mathrm{n}}$ is the vertical compressive stress, calculated as:

$$
\sigma_{n}=N / b_{w} h_{w 0}
$$

The relationship between $f_{t 0}$ and the tensile strength of the UHPC specimen is:

$$
f_{t 0}=f_{t} /\left(1+\alpha_{f} \lambda_{f}\right)
$$

$\alpha_{\mathrm{f}}$ is the coefficient of influence of the low tensile strength of the steel fibres, which is 0.15 from [12], and $\lambda_{f}$ is a characteristic parameter of the steel fibre content,

$$
\lambda_{f}=\rho_{f} l_{f} / d_{f}
$$

This can be calculated from this.

Cracking load:

$$
F_{c r}=0.67 f_{t o} b_{w} h_{w 0} \sqrt{1+\frac{N}{b_{w} h_{w 0} f_{t o}}}
$$

It is verified that the actual inclined section cracking load measured by the above formula differs from the actual value by a factor of 1.12 .

The shear bearing capacity consists of two components, the shear force and the horizontal shear force to which the concrete is subjected, and is calculated by the formula:

$$
V=0.67 f_{t o} b_{w} h_{w 0} \sqrt{1+\frac{N}{b_{w} h_{w 0} f_{t o}}}+f_{y v} \frac{A_{s v}}{s} h_{0}
$$

The shear load capacity of UHPC shear walls under repeated loading is reduced by $20 \%$ compared to monotonic loading. This equation is applicable to the calculation of the shear bearing capacity of UHPC shear walls.

Secondly, the shear bearing capacity under seismic action is also derived as follows:

$$
V=0.54 f_{t o} b_{w} h_{w 0} \sqrt{1+\frac{N}{b_{w} h_{w 0} f_{t o}}}+0.8 f_{y v} \frac{A_{s v}}{s} h_{0}
$$

The second formula is in good agreement with the measured values when tested against four specimens in the literature for lasting shear damage. Therefore, the shear bearing capacity of UHPC shear walls can be calculated according to Equation (9) in practical engineering.

Fang and $\mathrm{Li}$ et al. cast high-strength concrete shear walls with high reinforcement ratio edge-constrained specimens to study their seismic performance. They built specimens of length* width* height $(1000 \mathrm{~mm} * 120 \mathrm{~mm} * 1600 \mathrm{~mm})$. Loads in both horizontal and vertical directions were equally applied to the specimens.

The hysteresis curves for two of the 06 and 07 specimens are shown in Figures 14,15, 16.

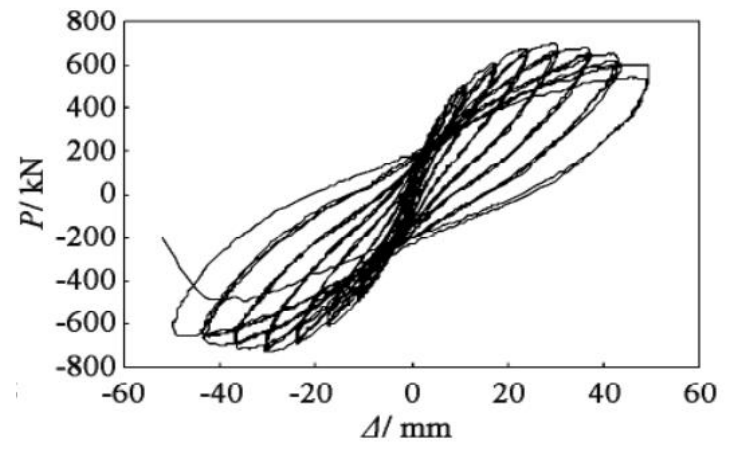

Fig 14. HPCSW06 Hysteresis curve.

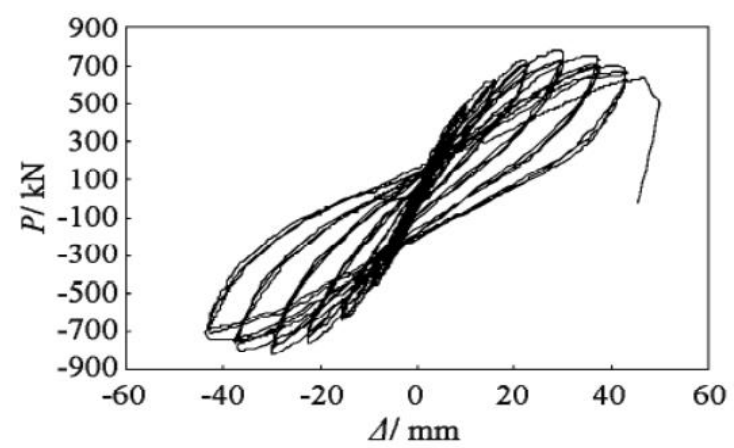

Fig 15. HPCSW07 Hysteresis curve.

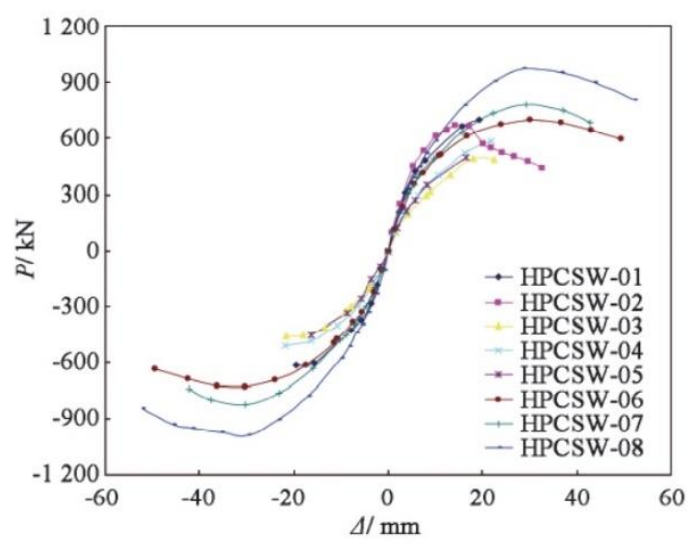

Fig 16. Test piece skeleton line

As seen from the skeleton curves, increasing the longitudinal reinforcement ratio of the edge restrained members effectively increased the load carrying capacity of the specimens. A comparison of specimens HPCSW06 and HPCSW-07 shows that, all other conditions being equal, the peak load of the specimen increases with the increase of the axial compression ratio, but the larger the axial compression ratio, the smaller the ultimate displacement of the specimen, the faster the load decays after reaching its peak, the deformation capacity of the shear wall becomes smaller and the displacement ductility becomes worse.

Its deformation capacity is quantified by the displacement ductility factor $\mu$.

$$
\mu=\Delta_{u} / \Delta_{y}
$$

where $\Delta \mathrm{y}$ is the yield displacement and $\Delta \mathrm{u}$ is the ultimate 
displacement. (See Fig. 17)

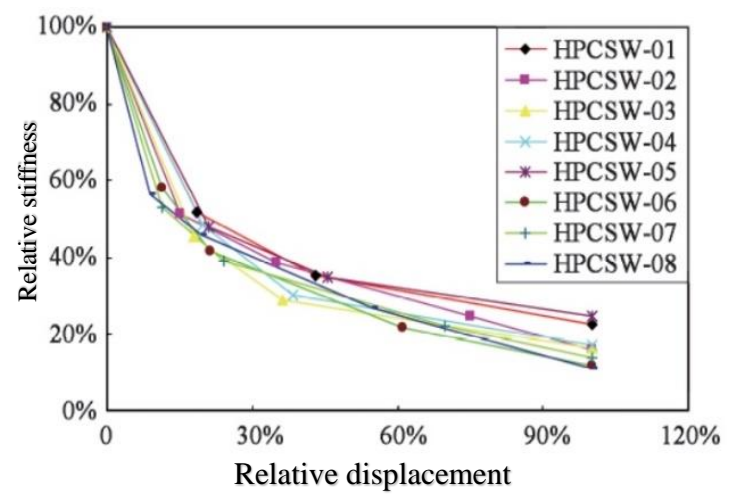

Fig. 17. Specimen stiffness degradation curves

As can be seen from the graph, the stiffness decay trend is more or less the same for each specimen, with the stiffness decaying fastest from the beginning of loading to cracking, faster during the process of cracking to apparent yielding, and the stiffness decay starting to slow down after yielding. The stiffness of the specimen gradually decreases with the development of the crack, which develops faster before the specimen yields.

The shear wall load-displacement curves of the specimens loaded monotonically were also simulated using the finite element model. The resulting experimental skeleton lines were compared with the actual skeleton lines.

Atlas 18-19.

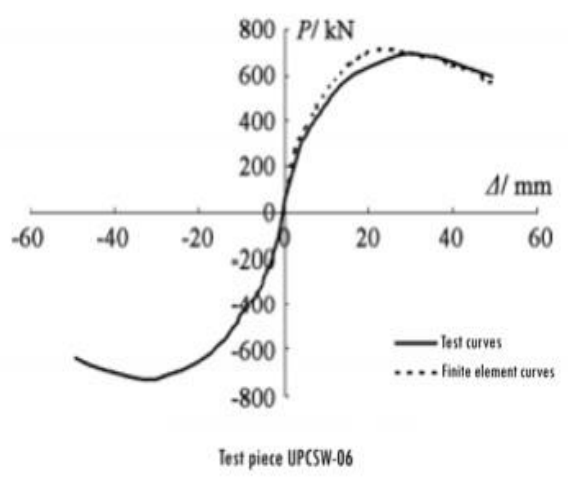

Fig 18. UPCSW-06 Skeleton wire

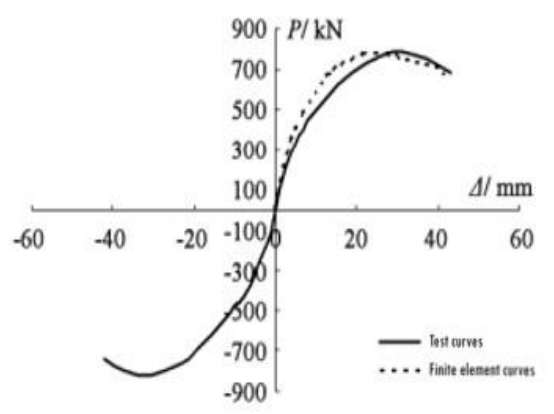

Test piece UPCSW-07

Fig 19. UPCSW-07 Skeleton wire.

As can be seen from the figure, the finite element and test skeleton curves can match well, especially the initial elastic phase is closer, but as the loading progresses, the two begin to deviate partially. In addition, the elastic stiffness of the finite element curve is slightly greater than that of the test curve, and the deformation corresponding to the peak load is slightly smaller than that corresponding to the peak load in the test curve, but the magnitude of the peak load is closer between the two.

This is probably due to the fact that the concrete used in ABAQUS is an ideal homogeneous material, whereas the test concrete is inhomogeneous and has certain defects, and the finite element analysis ignores the adhesive slip between the concrete and the reinforcement.

\section{Analysis of this article}

Shear wall finite element model: This paper uses three modules of ABAQUS modelling and an overall reinforcement network to achieve a finite element simulation of the UHPC shear wall. The overall model is composed of three modules: foundation beam: length*width*height $(1700 \mathrm{~mm} * 600 \mathrm{~mm} * 500 \mathrm{~mm})$; shear wall section length*width*height $\left(700 \mathrm{~mm}^{*}\right.$ $100 \mathrm{~mm} * 1400 \mathrm{~mm}$ ); loading beam above the shear wall length*width*height $(700 \mathrm{~mm} * 300 \mathrm{~mm} * 200 \mathrm{~mm})$. The concrete materials are all UHPC ultra-high performance concrete. The overall concrete protection layer thickness is taken as $25 \mathrm{~mm}$.

The shear wall is equipped with concealed columns at both ends within $100 \mathrm{~mm}$. HRB400 is used for the longitudinal reinforcement of the concealed columns, HPB300 is used for the vertical and horizontal reinforcement of the wall and the hoop reinforcement of the concealed columns.

The load beam is bundled with 11 hoop bars, the shear wall is composed of 30 layers of horizontal reinforcement and 8 concealed columns of longitudinal reinforcement, in order to strengthen the overall stability of the components concealed columns of longitudinal reinforcement through the three model components. The lower foundation beam consists of 23 rows of hoop bars and 4 lumbar bars with 4 horizontal bars to form a reinforcement skeleton. The model is shown in Figure 1 and the finite element model in Figure 20-21.

The finite element model is divided into the connection of the components: the reinforcement mesh parts are fixed together using the Tie command The concrete is bonded to the reinforcement skeleton using the Embedded region The UHPC material is defined using the plastic damage model and the parameters are shown in Table 1.

The compressive behaviour is shown in Table 2. The tensile behaviour is shown in Table 3 .

Table 1. UHPC material parameters

\begin{tabular}{|c|c|c|c|c|}
\hline $\begin{array}{c}\text { Expansion } \\
\text { angle }\end{array}$ & Eccentricity & $\begin{array}{c}\mathrm{fb} 0 / \\
\mathrm{fc} 0\end{array}$ & $\mathrm{k}$ & $\begin{array}{c}\text { Viscosity } \\
\text { parameters }\end{array}$ \\
\hline 56 & 0.1 & 1.16 & 0.67 & $5 \mathrm{E}-005$ \\
\hline
\end{tabular}


Table 2. Parameters of compressive behaviour

\begin{tabular}{|c|c|c|}
\hline & Yield stress & Inelastic strain \\
\hline 1 & 124 & 0 \\
\hline 2 & 138 & 0.001 \\
\hline 3 & 76 & 0.009 \\
\hline
\end{tabular}

Table 3. Tensile behaviour parameters

\begin{tabular}{|c|c|c|}
\hline & Yield stress & Cracking strain \\
\hline 1 & 0.7 & 0 \\
\hline 2 & 9.7 & 0.0035 \\
\hline 3 & 2.1 & 0.05 \\
\hline
\end{tabular}

Table 4. Reinforcement parameters

\begin{tabular}{|c|c|c|}
\hline $\begin{array}{c}\text { Types of } \\
\text { reinforcing steel }\end{array}$ & $\begin{array}{c}\text { Yield strength } \\
\text { standard value } \\
\text { /MPa }\end{array}$ & $\begin{array}{c}\text { Modulus of } \\
\text { elasticity } \\
/ \mathrm{GPa}\end{array}$ \\
\hline HPB300 & 300 & 210 \\
\hline HRB400 & 400 & 200 \\
\hline
\end{tabular}

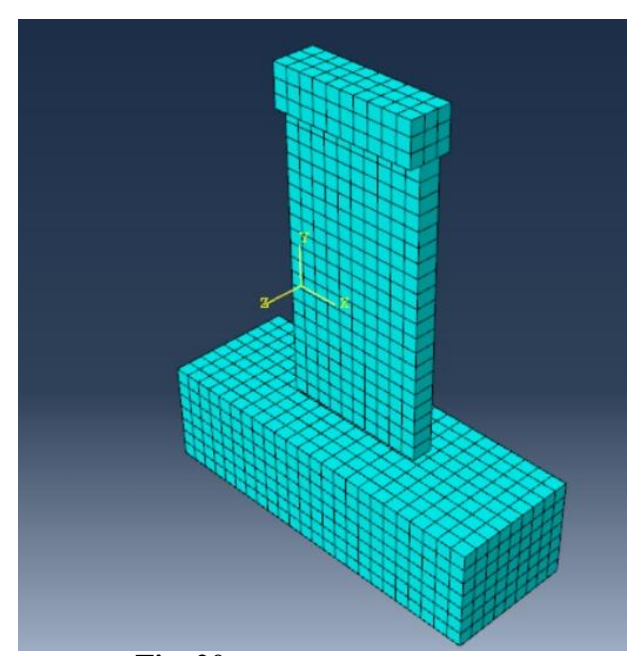

Fig. 20. Finite element model
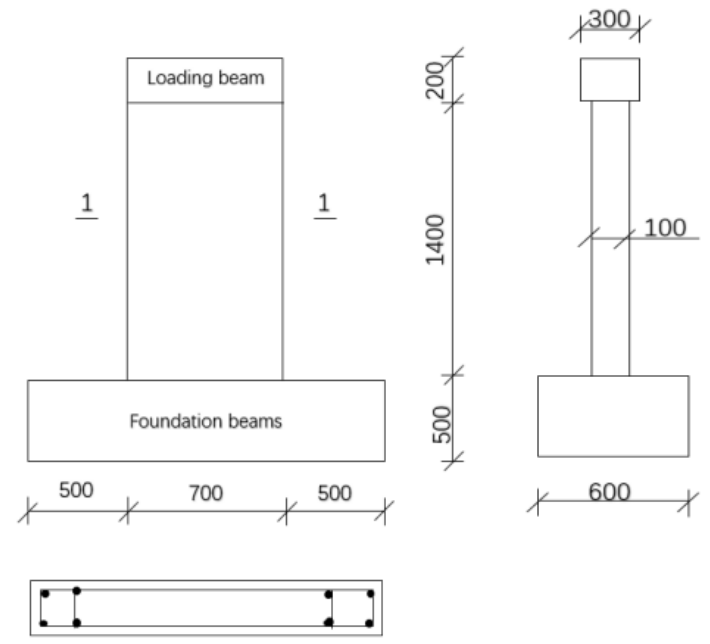

Fig. 21. Schematic diagram of geometry and reinforcement.

In this experiment, the foundation beam was fixed around, and on this basis, $54 \mathrm{kn}$ force was loaded on one side of the loading beam to observe the bending moment distribution and the energy dissipation capacity of the concrete. In terms of the experimental results, the shear resistance of the UHPC super high performance concrete shear wall far exceeds that of ordinary concrete, after the application of horizontal load, the maximum bending moment out of the loading beam action surface and shear wall connection and shear wall and foundation beam away from the loading surface of the two places, the bearing moment is mainly distributed in these two points of the line part, from the edge to the centre of the moment distribution gradually weakened, roughly the same value of each bending moment into The bending moments of roughly the same value are distributed in parallel in strips. It is worth noting that the shear wall near the foundation beam on the same face of the loading point also bears part of the bending moment, and the value is smaller compared to the central part of the same part of the shear wall, supposedly because in the overall modelling, the part of the shear wall connected to the foundation beam is restricted from moving, thus causing the bending moment to be transferred upwards, which is also a certain reason why there is no bending moment at the point where the shear wall is connected to the foundation beam by the loading point. There is also no bending moment in the middle of the shear wall away from the loading surface, which is supposed to be borne by the corresponding bottom part.

As the load increases, the overall moment distribution of the shear wall does not change much and no cracks appear at the loading point of $54 \mathrm{kn}$. The overall shear bearing capacity is very good. And the energy consumption is excellent.

Compared to conventional concrete, UHPC ultra-high strength concrete has a more excellent compressive and shear bearing capacity. The concrete itself has rapid initial development and high mid to late compressive strength, which can be used to reinforce and repair some stainless steel plates and expensive organic chemical polymers, thereby controlling costs and maintaining the integrity of the concrete management system. The high compressive strength and its impact resistance are also useful in defence and security constructions and in unique constructions where high load-bearing capacity is required; the high compactness and excellent corrosion resistance allow it to be used as a decorative material on the exterior of buildings.

\section{Conclusion}

The shear and compressive capacities of UHPC shear walls are much higher than those of ordinary concrete shear walls. In the loading, firstly, the UHPC shear wall was loaded with the forces that ordinary concrete can withstand and it was found that no cracks appeared in the UHPC shear wall, and by increasing the magnitude of the loading force, it was found that the bearing capacity of the UHPC shear wall was several times that of the ordinary concrete shear wall. Secondly, it was found that most of the bending moments were distributed in the connection between the loading beam and the shear wall in the acting plane and in the connection between the diagonal pair of shear wall and the foundation beam. These two points can be strengthened in future practical works. Overall UHPC shear walls are several times more capable than ordinary concrete shear walls in all aspects and are very promising for research and market. 


\section{References}

1. P. Richard, M. Cheyrezy, Composition of reactive powder concretes, Cement Concr. Res. 25 (7) (1995) 1501-1511.

2. Gao Xiaolong,Wang Junyan,Guo Junyuan,Liu Chao. Axial tensile mechanical properties and intrinsic structure relationship model of ultra-high performance concrete under cyclic loading[J/OL]. Journal of Composites:1-11[2021-01-06].

3. Wang Yuan. Progress in the application of ultra-high performance concrete in bridge engineering $[\mathrm{J}]$. Shaanxi Construction, 2020(08): 41-46.Structures, China Architecture \& Building Press, Beijing, 2018.

4. FANG Xiaodan, LI Zhaolin, WEI Hong, JIANG Yi. Experimental study on the seismic performance of high-strength concrete shear walls with high reinforcement rate edge restrained members $[\mathrm{J}]$. Journal of Building Structures,2011,32(12):145-153.

5. Zhong Yidong, Tong Xiaolong, Gan Wenju. Analysis of shear bearing capacity of ultra-high performance concrete shear walls[J]. Journal of Hunan Institute of Technology (Natural Science Edition),2015,28(01):55-58+76.

6. Zhang Danping, Liu Feng, Li Gu, Chen Yingqin. Current status and outlook of ultra-high performance concrete research[A]. Tianjin University, Tianjin Steel Structure Society. Proceedings of the 17th National Symposium on Modern Structural Engineering[C]. Tianjin University, Tianjin Steel Structure Society:Academic Committee of the
National Symposium on Modern Structural Engineering,2017:8.

7. Xiaolong Tong,Zhi Fang,Xiao Luo,Lan Gong. Study on shear capacity of ultra-high performance concrete squat shear walls $[\mathrm{J}]$. Case Studies in Construction Materials,2020,12.

8. Nong Decai, Zheng Qizhen, Long Libo, Ma Yueqiang, Chen Gang. Research on the application of ultra-high performance concrete in assembled concrete shear walls[J]. China Water Transport(Second Half Moon),2020,20(04):242$243+246$.

9. Xu Glory. Experimental study on uniaxial properties and intrinsic model of hoop-constrained ultra-high performance concrete[D]. Southwest Jiaotong University,2019.

10. Tian Sheng, Luo Jiqing, Zou Zhao Yong, Yan Banfu, Zhou Zhimin, Chen Juntao. Design and construction of transverse ultra-high performance concrete rigid arch bridges[J]. Highways,2020,65(10):170-175.

11. Xue Shicheng. Analysis of the force performance of RUHPC combined precast shear walls[D]. Harbin Institute of Technology, 2020. (In Chinese)

12. Hunan Provincial Department of housing and urban rural development, DBJ 43/T 325-2017 Technical Specification for Reactive Podwer Concrete Structures, China Architecture \& Building Press, Beijing, 2018. 